\title{
Metodski postupak obuke udarca po lopti glavom u fudbalu
}

\author{
Molnar Slavko \\ Gušić Marko \\ Fakultet sporta i fizičkog vaspitanja, Novi Sad
}

\begin{abstract}
Head play is very important characteristic of a football game. A large number of actions ends with head striking the ball, because this technical element is used in both defensive and offensive aspects of the football game. Therefore, training of this technical element is essential for the result of a football match. Precisely for this reason the methodological approach of head striking ball training, which is implemented in the training process of football players, is extremely important part of training that contributes greatly to the success of the entire football career of every football player.
\end{abstract}

Keywords: football, methodical process of training, striking the ball with head.
Sažetak: Igranje glavom je veoma važna karakteristika fudbalske igre. Veliki broj akcija završava se udarcem po lopti glavom, jer se ovaj tehnički elemenat koristi i u odbrambenim i u napadačkim segmentima fudbalske igre. Zbog toga je obučenost izvođenja ovog tehničkog elementa od suštinskog značaja za krajnji rezultat na fudbalskoj utakmici. Upravo iz tog razloga metodski postupak obuke izvođenja udaraca po lopti glavom, koji se sprovodi u trenažnom procesu fudbalera, predstavlja izuzetno važan deo obučavanja, koji u velikoj meri doprinosi uspešnosti u celokupnoj fudbalskoj karijeri svakog fudbalera.

Ključne reči: fudbal, metodski postupak obuke, udarci po lopti glavom.

Rad je primljen 24.09.2015.

Odobren 24.10.2015.

Kontakt podaci:

Slavko Molnar

Fakultet za sport i fizičko vaspitanje

Novi Sad, Lovćenska 16

Tel: +381641171720

E-mail: molslavko@gmail.com 


\section{Uvod}

Fudbalska igra, prema verodostojnim istorijskim zapisima, potiče od raznih praigara, koje su se igrale kod: Kineza, Grka i Rimljana. Koreni fudbala, odnosno, njegovi počeci i prvi period razvoja u prvi plan su istakli tehniku u čijem su prisustvu taktika i fizička priprema imale manje značajnu ulogu. Dalji razvoj fudbala, pored dostizanja određenog nivoa fudbalske tehnike u praksi, u potpunosti izjednačava po vrednosti i taktiku i fizičku pripremu. Međutim, kada se sagleda procentualna zastupljenost: tehničke, fizičke, taktičke i teoretske pripreme, može se videti da se sa najmlađim fudbalerima u radu na treninzima, najviše posvećuje pažnja tehničkoj pripremi.

„Pod pojmom tehničke pripreme treba podrazumevati blagovremeno obučavanje određenih elemenata, koji odgovaraju motoričkim sposobnostima i razvoju nervnog sistema tog uzrasta. Rad na obučavanju tehnike fudbala treba da započne pre puberteta (10-12 godina). Dete se mora upoznati sa osnovama tehnike jos pre toga, $\mathrm{u}$ slobodnoj igri, jer u protivnom igrači teško postižu vrhunske rezultate.“" (Molnar i Radosav 2012).

Tehnička priprema se deli na nekoliko delova, ali udarci po lopti se ubrajaju u najvažniji segment ove vrste pripreme. Oni mogu biti udarci po lopti nogom i udarci po lopti glavom.

Koliko je značajan ovaj segment fudbalske igre, potvrđuje i činjenica da su četiri najuspešnije reprezentacije na EP 2008. ostvarile ukupno 7 efikasnih napada u kojima je gol postignut glavom. Prosečno je svaka od ovih reprezentacija ostvarila 1,75 ovakvih napada. $\mathrm{Na}$ pomenutom prvenstvu četiri najuspešnije ekipe u proseku su postiglu $23 \%$ golova glavom (Simić 2008).

\section{Udarci po lopti glavom}

$\mathrm{Za}$ vreme igre fudbaleri često dolaze $u$ situaciju da loptu udare glavom. To su najčešće: izbijanja poluvisokih i visokih lopti ispred svoga gola, udarci na gol, razna dodavanja saigraču, ili prekidanje akcija protivnika. Ovom elementu tehnike treba u obuci posvetiti dovoljno pažnje, tim pre što pripada redu složenih elemenata, a igrači ga nerado uče sami, zbog straha od udarca ili mogućnosti sudara glavom sa protivnikom.

Jačina udarca uglavnom zavisi od: brzine kretanja igrača, brzine kretanja gornjeg dela tela prilikom udarca po lopti, brzine kretanja lopte i pravilnosti izvođenja udarca.
Udarci po lopti glavom dele se na:

- udarca čelom i stranama čela,

- udarac temenom,

- udarac potiljkom.

\section{Udarci po lopti čelom}

Ovi udarci izvode se iz mesta i iz kretanja, sa i bez skoka i iz pada. Oni su vrlo snažni, a udarac prednjim delom čela nešto je precizniji od udarca stranama čela.

Pri obuci udarca po lopti čelom iz mesta, pre izvođenja samog udarca, treba obratiti pažnju na mali iskorak napred i na zamah telom unazad. Sam udarac izvodi se naglim pokretom tela unapred uz prenošenje težine tela sa noge koja se nalazi iza, na nogu koja se nalazi ispred tela.

Udarac glavom treba da se izvede otvorenim očima i loptu treba pratiti telom na što dužem putu.

Pri obuci udarca po lopti čelom posle odskoka, zamah za udarac i sam udarac se ne razlikuju od udarca iz mesta. Kod izvođenja ovog udarca razlikujemo nekoliko faza $i$ to: pripremna faza, odraz, let i doskok (Joksimović 2001). Važno je napomenuti da doskok mora biti na obe noge koje postavljamo odmah u dijagonalni stav, da bismo mogli da nastavimo kretanje bez dodatnog koraka.

Metodski postupak:

- opis tehničkog elementa, njegova primena i značaj,

- demonstracija udarca,

- uvežbavanje pokreta bez lopte (Slika 1),

- igrač sam sebi nabacuje loptu i izvodi udarac iz mesta, tako da lopta jednom odskoči od tla do partnera (Slika 2),

- igrač sam sebi nabacuje loptu i dodaje do partnera (Slika 3),

- partner nabacuje loptu, a igrač izvodi udarac iz mesta (Slika 4),

- partner nabacuje loptu i igrač izvodi udarac iz skoka (Slika 5),

- partner nabacuje loptu, a igrač povezuje udarac iz skoka i iz kretanja. 


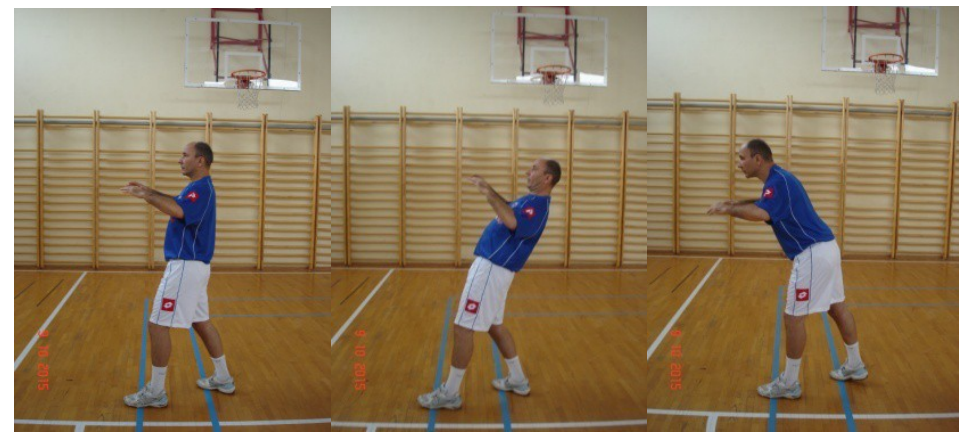

Slika 1. Uvežbavanje pokreta bez lopte

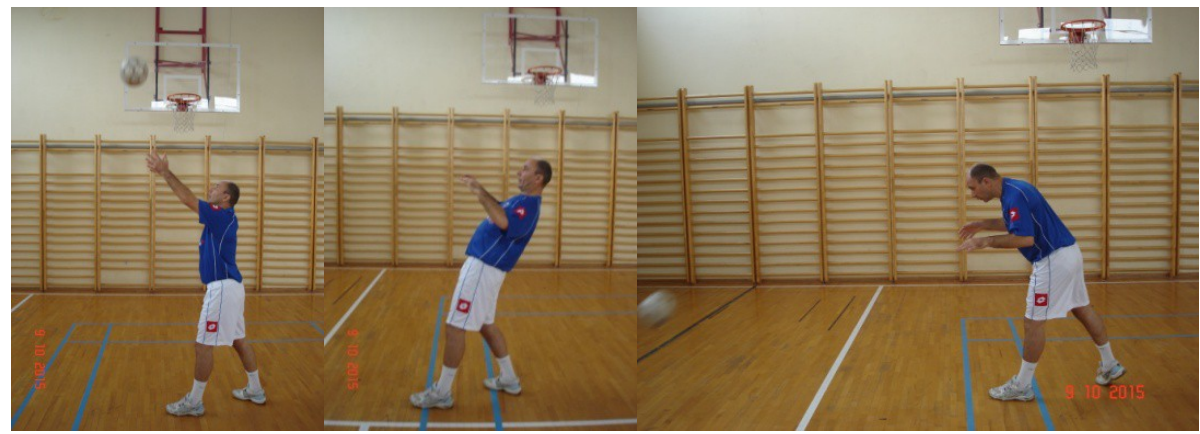

Slika 2. Igrač sam sebi nabacuje loptu i izvodi udarac iz mesta, tako da lopta jednom odskoči od tla do partnera

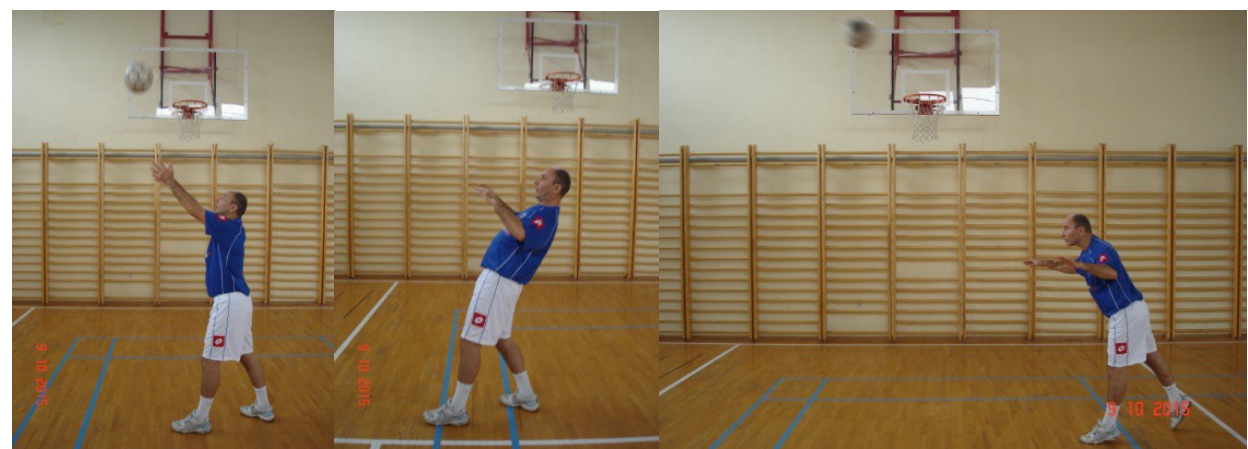

Slika 3. Igrač sam sebi nabacuje loptu i dodaje do partnera

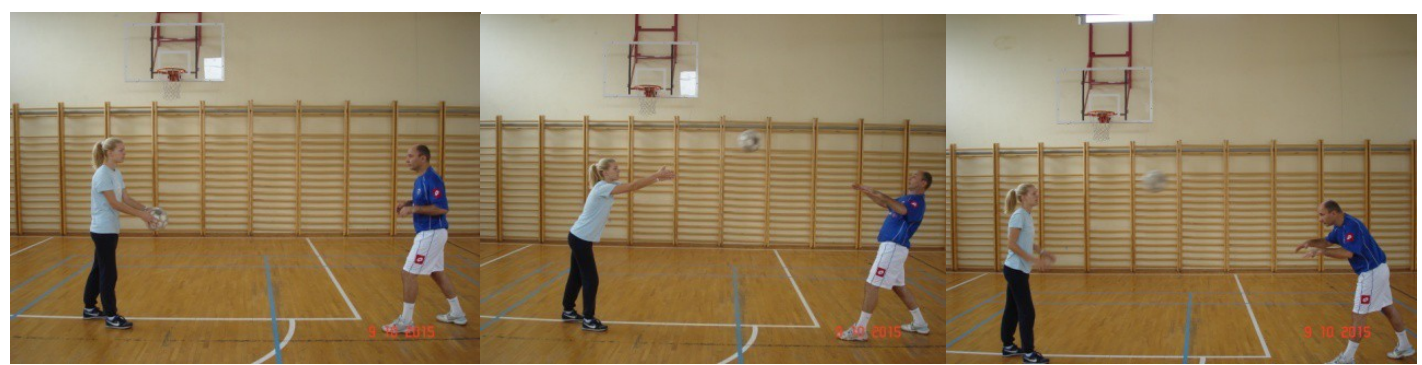

Slika 4. Partner nabacuje loptu, a igrač izvodi udarac iz mesta

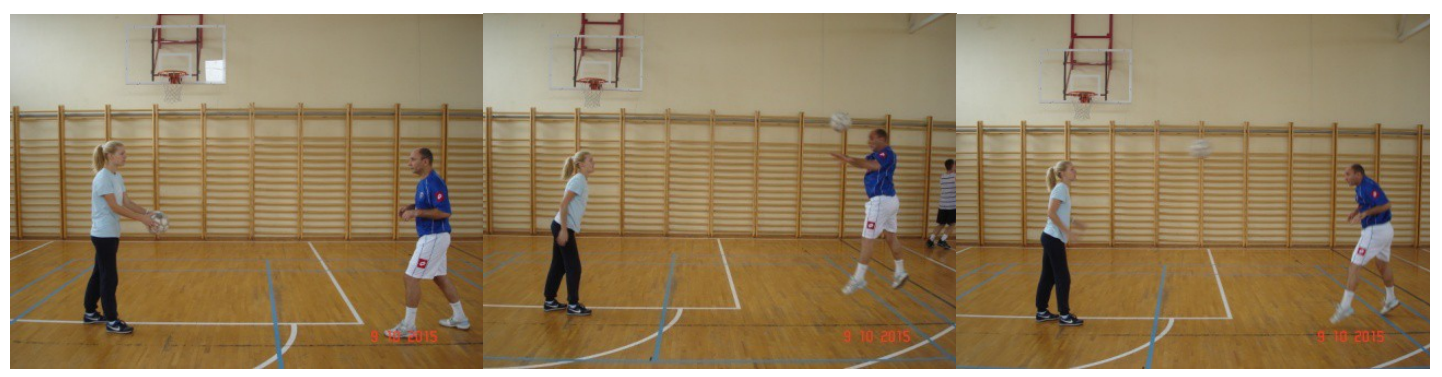

Slika 5. Partner nabacuje loptu i igrač izvodi udarac iz skoka 


\section{Udarac po lopti stranama čela}

Udarac po lopti stranama čela može da se izvede iz mesta, kretanja i skoka.

Igrač se postavlja bočno u odnosu na loptu. Prilikom uzimanja zamaha, težina tela se prebacuje na dalju nogu u odnosu na pravac iz kod dolazi lopta, uz otklon na istu stranu. Da bismo izveli udarac, prebacujemo težinu tela (bez uvrtanja) na bližu nogu u odnosu na pravac iz kog dolazi lopta, uz opružanje dalje noge.

Metodski postupak:

- opis tehničkog elementa, njegova primena i značaj,

- demonstracija udarca,

- uvežbavanje pokreta bez lopte (Slika 6),

- igrač sam sebi nabacuje loptu i izvodi udarac iz mesta, tako da lopta jednom odskoči od tla do partnera (Slika 7),

- igrač sam sebi nabacuje loptu i dodaje do partnera (Slika 8),

- partner nabacuje loptu, a igrač izvodi udarac iz mesta (Slika 9),

- partner nabacuje loptu i igrač izvodi udarac iz skoka (Slika 10),

- partner nabacuje loptu, a igrač povezuje udarac iz skoka i iz kretanja.

\section{Udarac po lopti glavom u padu}

Udarci čelom i stranama čela se izvode i u padu, na taj način što se igrač glavom baca napred u susret lopti. Odraz može biti jednom ili sa obe noge. Da bismo ublažili pad na zemlju, dočekujemo se posle izvođenja udarca na obe ruke.

Metodski postupak:

- opis tehničkog elementa, njegova primena i značaj,

- uvežbavanje pada bez lopte (Slika 11),

- dodavanje lopte po tlu između partnera (Slika 12),

- partner nabacuje rukom nisku loptu; izvodi se u padu udarac glavom sa prizemljenjem povaljkom (bacanje iz počučnja i iz mesta) (Slika 13),

- partner nabacuje rukom nisku loptu, izvodi se u kretanju udarac glavom u padu.

$\mathrm{Za}$ obuku udarca čelom i stranama čela dobro je koristiti i stalak sa visećom loptom (možemo podešavati visinu lopte).

\section{Udarac po lopti temenom}

Udarac temenom se koristi da bi se produžio let lopti. Ovaj udarac je veoma slab i za njegovu obuku ne treba trošiti mnogo vremena. Bitno je da igrač stoji u dijagonalnom stavu povijenih kolena, koja opruža u momentu udarca po lopti, ruke su ispred tela blago savijene $u$ laktovima.

Metodski postupak:

- opis tehničkog elementa, njegova primena i značaj,

- demonstracija udarca,

- uvežbavanje pokreta bez lopte,

- partner nabacuje loptu, a igrač izvodi udarac iz mesta (Slika 14),

- partner nabacuje loptu, a igrač izvodi udarac iz kretanja.

\section{Udarac po lopti potiljkom}

Udarac potiljkom se koristi za vraćanje lopte golmanu ili saigraču, kada lopta pada vertikalno iz visine ili kada lopta visoko odskoči od zemlje. Kao i prethodni, tako je i ovaj udarac slab, te mu ne treba poklanjati mnogo vremena na treninzima.

Igrač je u dijagonalnom stavu. Neposredno pred udarac po lopti izvodi mali pretklon, da bi naglim opružanjem trupa sustigao loptu i udario potiljkom po njoj. Međutim, zbog rizika od povrede koji se javlja kod izvođenja ovog udarca, treba ga izbegavati u igri i umesto njega koristiti udarac po lopti temenom.

Metodski postupak:

- opis tehničkog elementa, njegova primena i značaj,

- demonstracija udarca,

- uvežbavanje pokreta bez lopte,

- partner nabacuje loptu, a igrač izvodi udarac iz mesta (Slika 15),

- partner nabacuje loptu, a igrač izvodi udarac iz kretanja. 


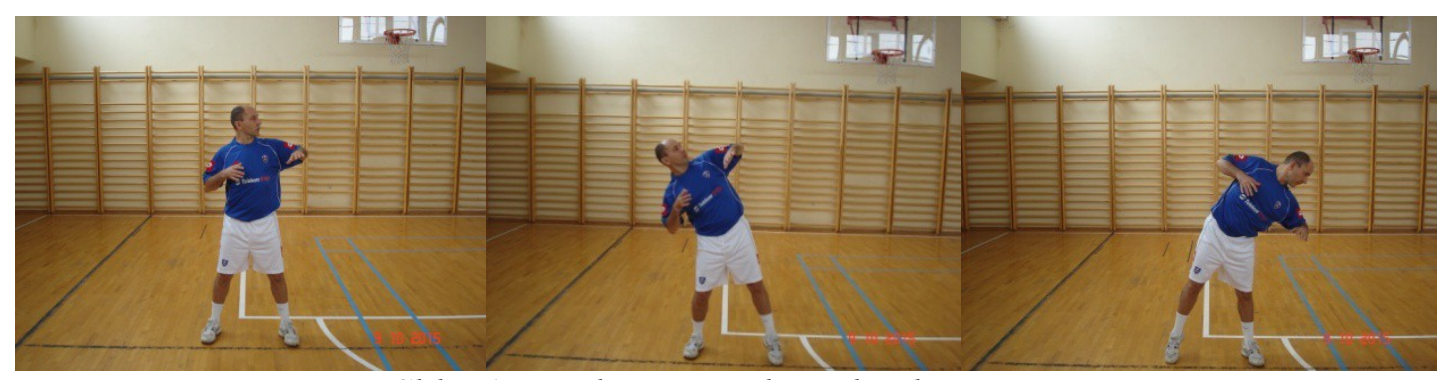

Slika 6. Uvežbavanje pokreta bez lopte

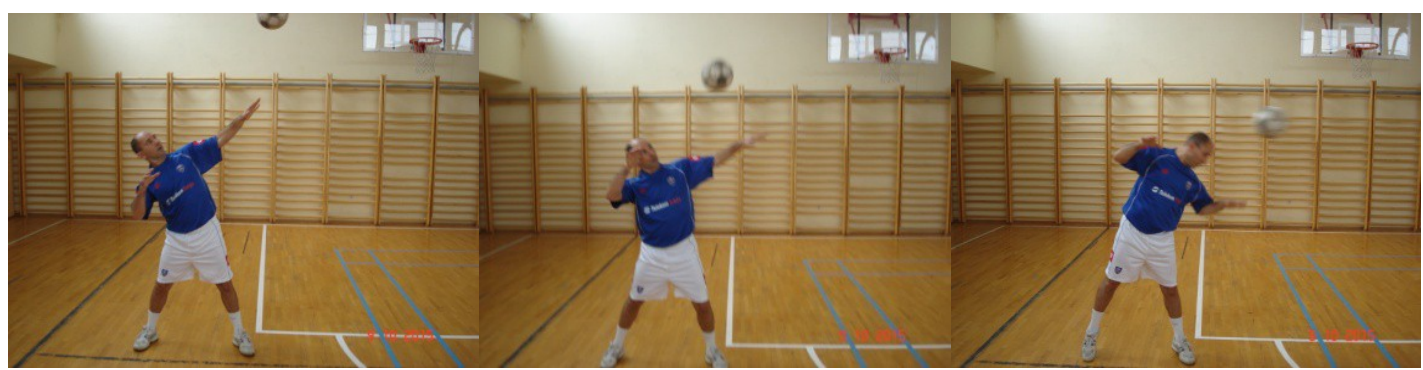

Slika 7. Igrač sam sebi nabacuje loptu i izvodi udarac iz mesta, tako da lopta jednom odskoči od tla do partnera

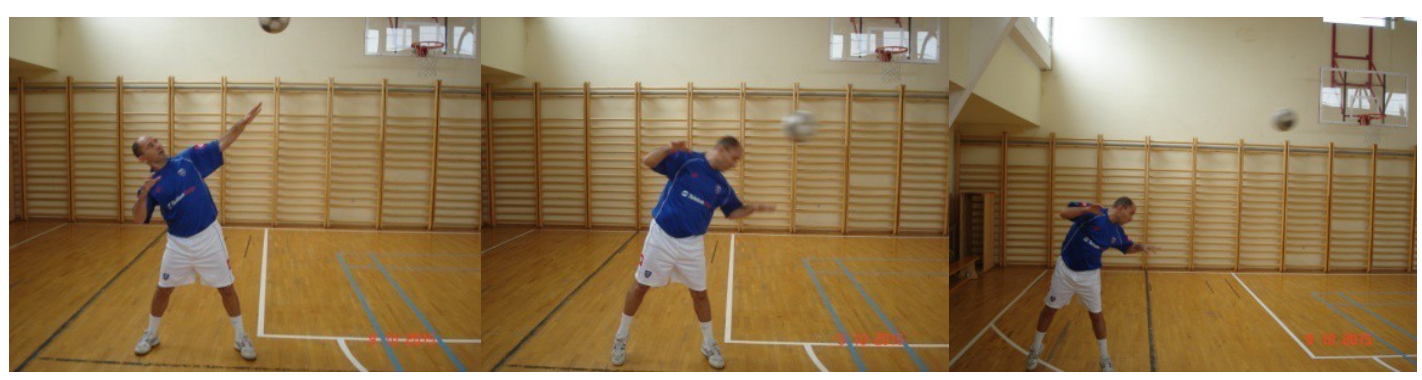

Slika 8. Igrač sam sebi nabacuje loptu i dodaje do partnera

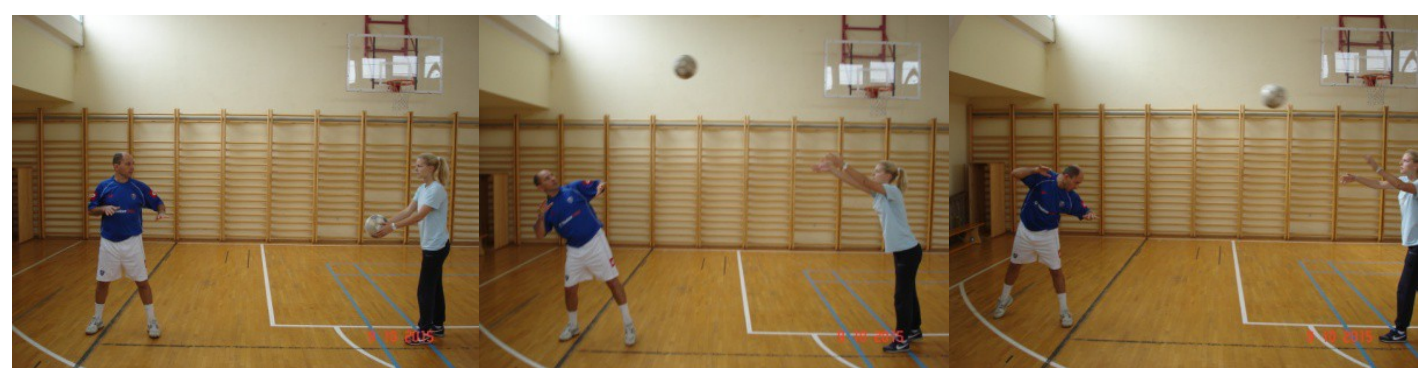

Slika 9. Partner nabacuje loptu, a igrač izvodi udarac iz mesta

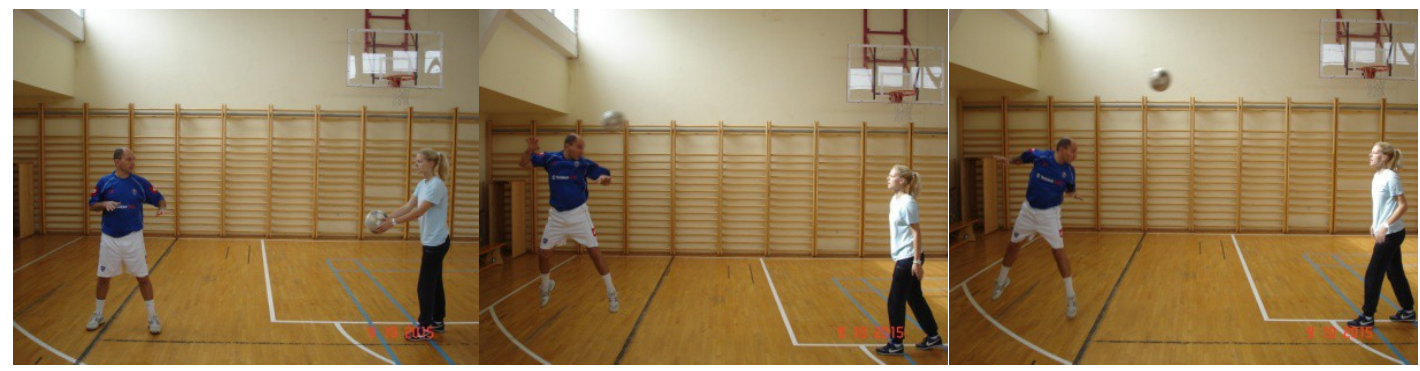

Slika 10. Partner nabacuje loptu i igrač izvodi udarac iz skoka 


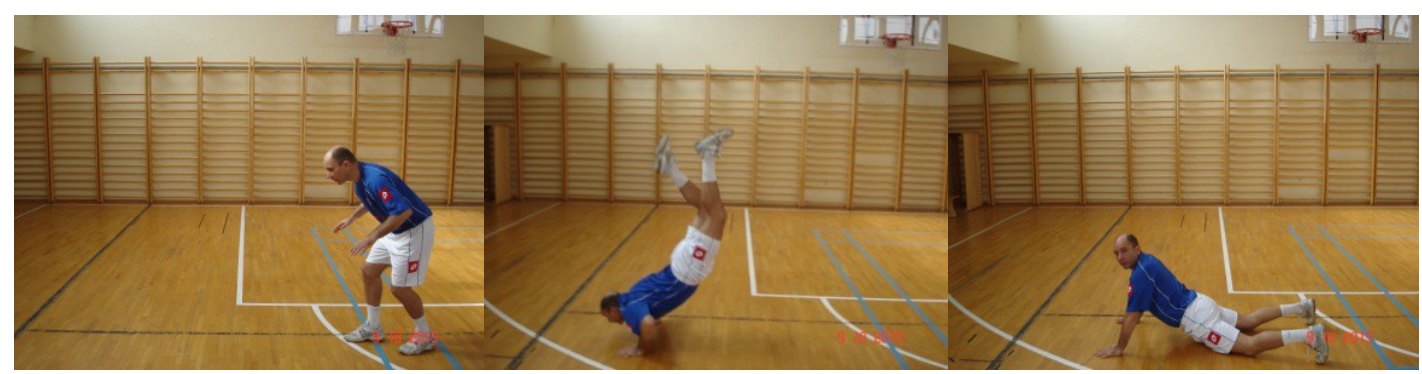

Slika 11. Uvežbavanje pada bez lopte

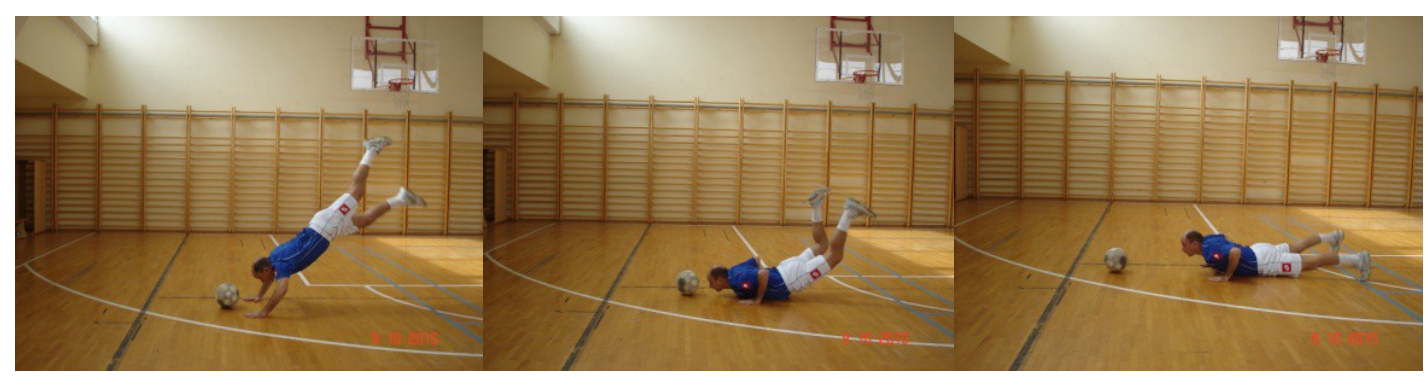

Slika 12. Dodavanje lopte po tlu između partnera
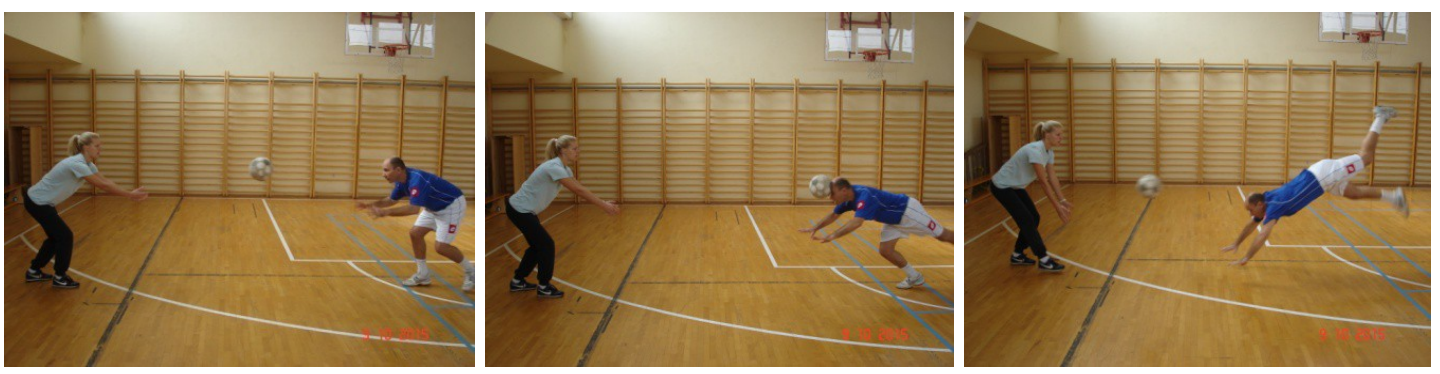

Slika 13. Partner nabacuje rukom nisku loptu; izvodi se u padu udarac glavom sa prizemljenjem povaljkom (bacanje iz počučnja i iz mesta)

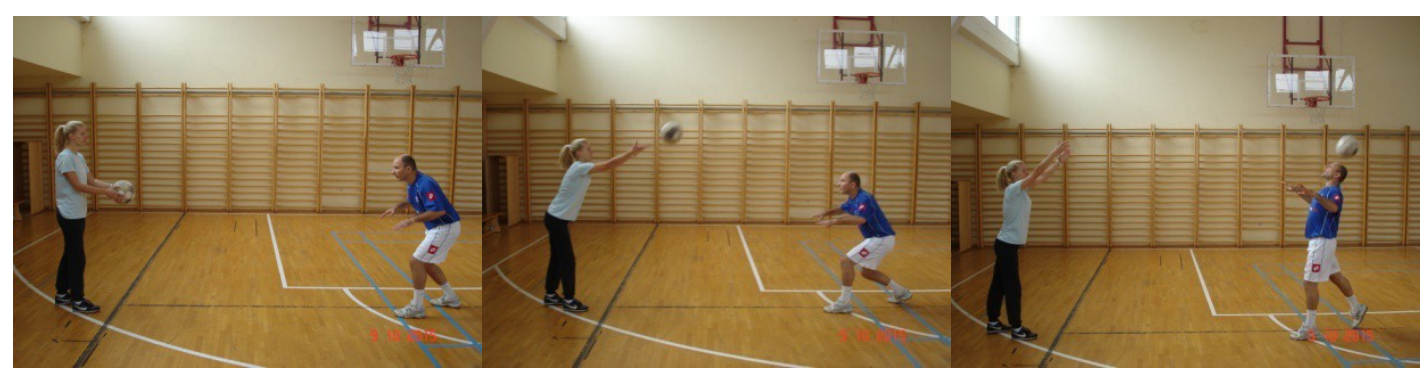

Slika 14. Partner nabacuje loptu, a igrač izvodi udarac iz mesta

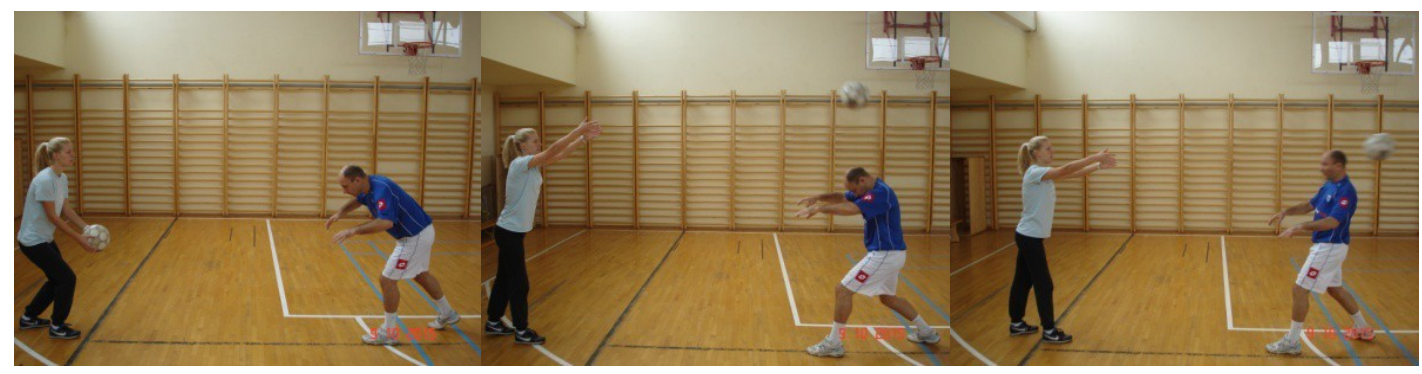

Slika 15. Partner nabacuje loptu, a igrač izvodi udarac iz mesta 


\section{Zaključak}

Rad na obuci tehnike udarca po lopti glavom treba početi u pionirskoj katergoriji (od 12. do 14 . godina) i ta faza obuke naziva se Faza neposredne obuke fudbalera (Joksimović 2007). Kod izvođenja ovoga tehničkog elementa, veoma je bitno njegovo pravilno izvođenje, jer ako se udarac izvede nepravilno može doći do povreda fudbalera, a samim tim kasnije i izbegavanje njegovog izvođenja $\mathrm{u}$ igri. Za izvođenje ovog tehničkog elementa izuzetno je značajna $i$ postupnost obučavanja, kojim se postepeno ojačava muskulatura cervikalnog dela kičmenog stuba, kao i muskulatura trbušne i leđne regije, kojim smanjujemo rizik od povređivaja, kao i eventualne pojave straha pri izvođenju ovog udarca kod mladih fudbalera. 


\section{Literatura}

1. Joksimović, A. (2007). Fudbal, tehnika i metodika. Niš: fakultet sporta i fizičkog vaspitanja.

2. Joksimović, S. (2001). Teorija tehnike fudbalske igre. Niš: Fakultet sporta i fizičkog vaspitanja.

3. Molnar, S. Radosav, R. (2012). Osnove fudbala. Novi Sad: Fakultet sporta i fizičkog vaspitanja.

4. Radosav, R., Molnar, S., Smajić, M. (2003). Teorija i metodika fudbala. Novi Sad: Fakultet fizičke kulture.

5. Simić B. (2008). Komparativna analiza taktičkog učinka najuspešnijih evropskih, afričkih $i$ južno-američkih fudbalskih reprezentacija na kontinentalnim takmičenjima. Magistarska teza, Beograd: Fakultet sporta i fizičkog vaspitanja. 